\title{
VENO-OCCLUSIVE DISEASE OF THE LIVER AND INDIAN CHILDHOOD CIRRHOSIS
}

\author{
BY \\ DERRICK B. JELLIFFE, GERRIT BRAS AND KANAI L. MUKHERJEE \\ From the Department of Tropical Medicine, Tulane University of Louisiana, New Orleans, U.S.A.*, the Department \\ of Pathology, University College of the West Indies, Jamaica, and the Calcutta School of Tropical Medicine, Calcutta, \\ India
}

(RECEIVED FOR PUBLICATION APRIL 24, 1957)

Cirrhosis of the liver is rare in childhood in the temperate zone and it is then usually due to some specific and traceable cause, such as Rhesus incompatibility, galactosaemia, congenital syphilis, in association with congenital abnormalities of the biliary apparatus, or following infective hepatitis. In most of the subtropics and tropics-at least according to present probably incomplete evidencecirrhosis in childhood is somewhat more common, but it is still infrequently seen, despite the fact that the condition may have a high incidence amongst adults.

There appear to be only two widely separated regions of the world from which cirrhosis in childhood has been commonly reported in the medical literature-the West Indian island of Jamaica and the subcontinent of India, especially the eastern States of Madras and Bengal.

As it has recently been possible for the writers collaboratively to have had experience in both regions, the present paper has been written in order to compare clinical and histological features of cirrhosis in childhood as seen in both Jamaica and Calcutta, West Bengal.

\section{VENO-OCCLUSIVE DISEASE OF THE LIVER}

Awareness that cirrhosis was common enough to be a public health problem among Jamaican children in the lower socio-economic groups was initiated by the original clinical accounts of McFarlane and Branday (1945), Roys (1948) and Waterlow (1948).

The work of Hill, Rhodes, Stafford and Aub (1953) clarified the clinical picture, initiated the investigation of the histology and suggested possible aetiological factors. More recently, Bras, Jelliffe and Stuart (1954) demonstrated the predominant role of an obliterating process in the hepatic vein

* Late of the Section of Maternal and Child Health, All-India Institute of Hygiene and Public Health, Calcutta, India. radicals in the morphogenesis, so that the condition was designated 'veno-occlusive disease of the liver' (V.O.D.).

Clinical Picture. The clinical picture has been described by Jelliffe, Bras and Stuart (1954a, 1954b), and may be summarized in the following three, often ill-defined, overlapping stages (Fig. 1): (1) Acute hepatomegaly $(2$ to $10 \mathrm{~cm}$.) developed suddenly in five to 10 days, mainly in young children of from 18 months to 3 years of age, often with ascites, frequently after non-specific upper respiratory tract infection and often subsiding with or without treatment in four to six weeks. (2) Subacute, persistent, firm hepatomegaly, with or without recurrent ascites, may occur spontaneously or after the acute stage; it may subside clinically, with a high protein diet or pass into the chronic state (Fig. 2). (3) Chronic, the clinical picture of cirrhosis, is shown in Fig. 3.

Recently, veno-occlusive disease has been shown to occur, although less commonly, in Jamaican adults (Stuart and Bras, 1955), while it has also been discovered in another West Indian island, Barbados (Stuart and Bras, 1956).

Morbid Anatomy. The sequence of histological change, as demonstrated by both liver biopsies and necropsies, has been described by Bras et al. (1954), by Bras and Watler (1955) and more recently it has been summarized by Bras and Hill (1956).

The initial lesion in the acute stage is a subendothelial intimal thickening, with partial occlusion of the lumen, in small and medium sized branches of the hepatic vein, associated with centrilobular congestion. If the condition persists, atrophy and loss of liver cell cords occurs followed by a centrilobular (non-portal) fibrosis. The intimal thickening in later stages is composed of fibrous tissue. The liver in chronic cases is diffusely, finely granular and macroscopically indistinguishable from 


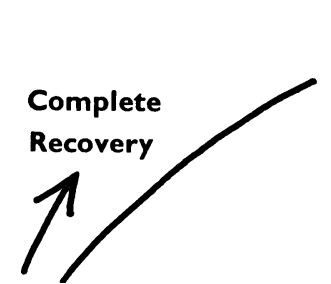

(a) ACUTE V.O.D.

(Sudden hepatomegaly, often ascites, usually in adequately nourished children $I_{1}$ to 3 years)

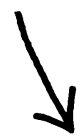

Rapid Death

(increasing jaundice, cholaemia)

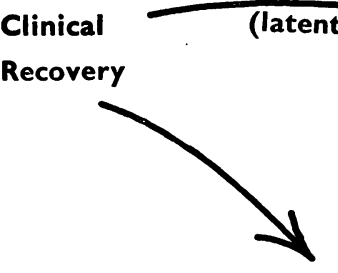

(b) SUB-ACUTE V.O.D.

(persistent firm hepatomegaly, with or without recurrent
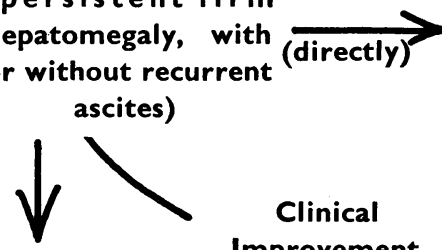

? Complete Recovery

(either spontaneously or with treatment)

\section{Clinical Improvement}

(b) \& (c) may be present with noclinical history of preceding illness.

FIG. 1.-Diagram of the clinical natural history of veno-occlusive disease.

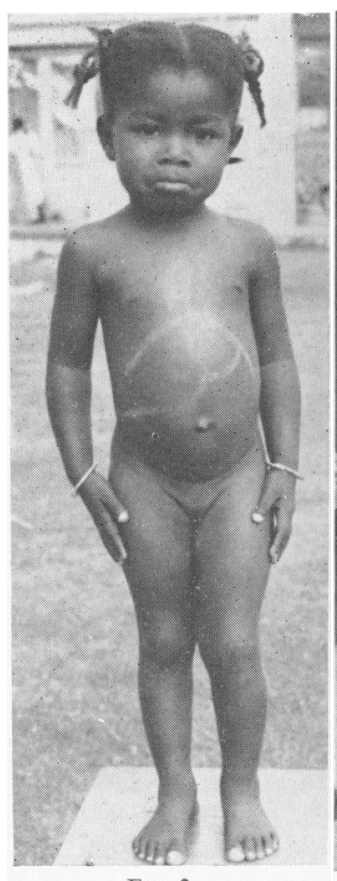

FIG. 2.

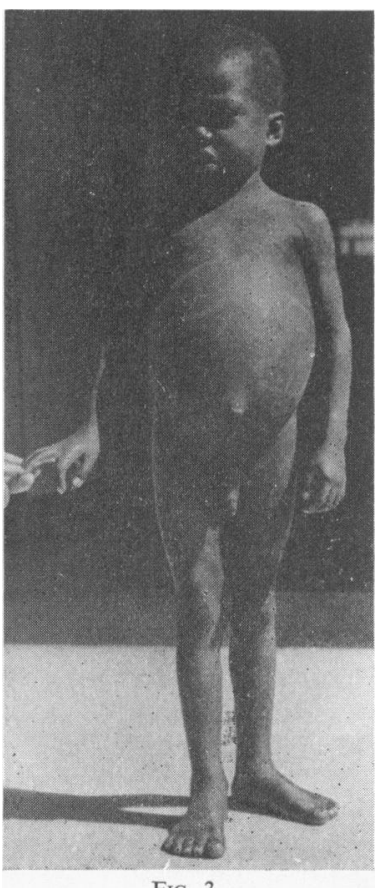

FIG. 3. early Laennec's cirrhosis, although histologically the cirrhosis is clearly not portal.

Aetiology. It has been postulated tentatively that veno-occlusive disease in Jamaican children may be due to the effect of an as yet unidentified toxin on the liver of undernourished children. The nature of this toxin is unknown, but the frequent association of cases of acute veno-occlusive disease with preceding respiratory tract infections, including whooping cough, may be significant, while the practice of drinking over 200 different varieties of homeprepared herbal infusions, known as 'bush-teas', may also be relevant (Asprey and Thornton, 1953). The latter hypothesis has received support from the recent report of the condition in a cow in Jamaica (Bras and Berry, 1956), and direct attempts to reproduce the disease in experimental animals fed on bush-teas have supported this theory. Moreover, Selzer and Parker (1951) described an outbreak which began as acute Chiari's syndrome caused by eating bread made from inadequately winnowed

FIG. 2.-A Jamaican girl with subacute veno-occlusive disease showing symptomless hepatomegaly only.

FIG. 3.-Jamaican boy with chronic veno-occlusive disease showing the picture of fully developed cirrhosis. 
wheat contaminated by a species of senecio, or ragwort, a common wild plant, while, even earlier, Davidson (1935) had demonstrated that retrosine, one of the alkaloids of senecio, produced an endothelial proliferation in the central and sublobular veins as its primary effect.

Recent studies (Bras, Berry and György, 1957) on experimental animals have shown that histological lesions identical to those of veno-occlusive disease can be reproduced in the livers of cattle and horses by feeding them with certain toxic plants.

\section{INDIAN CHILDHOOD CIRRHOSIS}

Since its original description as a clinical entity by Sen (1887), it has been recognized that cirrhosis of the liver in young children is a not uncommon condition in various parts of India, and a considerable, somewhat repetitive literature has grown up on the subject, almost entirely confined to Indian medical journals (Radakrishna Rao, 1934). An authoritative review of the present situation has been published recently by the Liver Diseases SubCommittee of the Indian Council of Medical Research (I.C.M.R.) (1955).

\section{Nomenclature}

A variety of different names have been employed at different times by various authors, including biliary cirrhosis (Gibbons, 1888), infantile cirrhosis of the liver (Lahiri, 1936), hypertrophic or biliary cirrhosis (Brahmachari and Brahmachari, 1938) and subacute toxic cirrhosis of infants (Radhakrishna Rao, 1935). None of these seem entirely satisfactory and; as the disease appears to affect young children rather than infants exclusively, the noncommittal term 'Indian childhood cirrhosis' (I.C.C.) will be used in the present account.

\section{Present Cases}

Diagnostic Criteria. Precise criteria for case selection were difficult to formulate. As the early symptoms are indeterminate and non-specific, children were selected initially by finding a firm or hard hepatomegaly, after exclusion as far as possible of other known causes of liver enlargement, such as kwashiorkor, malaria, kalar azar, infective hepatitis and congenital syphilis. Associated splenomegaly, the development of a collateral circulation, ascites and jaundice were regarded as corroborative evidence, but not necessary for diagnosis.

This classification is obviously unsatisfactory when it is recalled that knowledge of the pathology of Indian children is rudimentary, especially as post-mortem examinations are rarely performed. It is quite probable that there are as yet unrecognized causes of hepatomegaly in early childhood in India, as for example, visceral larva migrans due to ingestion of ova of the dog or cat roundworm (Toxocara canis, T. cati) (Beaver, Snyder, Carrera, Dent and Lafferty, 1952), or even perhaps as a result of the continuous transhepatic migration of larvae of $A$. lumbricoides, an almost universal parasite in children in some parts of India.

In the present series, liver biopsies were undertaken whenever possible, although this was often not feasible. Of the first 13 cases, nine were biopsied with a modified Vim-Silverman needle, and, of these, four showed no abnormality histologically and one demonstrated only moderate fatty change. All five of these children showed only a moderate, firm enlargement of the liver, with no corroborative evidence of cirrhosis. In view of these negative findings, together with the present somewhat controversial and uncertain evidence of any early or specific histological lesions in this condition, it was decided not to include these five cases and to select cases more rigidly in future.

The present series is, therefore, composed of 15 children seen at either the Out-patient Clinic of the Calcutta School of Tropical Medicine or at the Child Welfare Clinic of the All-India Institute of Hygiene and Public Health. They were admitted to hospital for full investigation whenever possible, but this was often not practicable as parents refused to allow their children to be admitted or beds were not available in the always busy and overcrowded ward.

Cases were only included if they showed the tentative diagnostic criteria of hepatomegaly, as previously described, together with at least one definite physical sign probably corroborative of cirrhosis, such as splenomegaly, dilated collateral circulation, ascites or jaundice, and/or histological evidence of hepatic fibrosis at liver biopsy or necropsy. It is realized that this classification is also open to criticism, especially as it excludes early cases about which very little is known.

Age Incidence. The average stated age at which children were brought to the clinic in the present small series was 3 years 5 months, with a range of from 11 months to 8 years 10 months. Apart from possible inaccuracies due to incorrect ages given by parents, it will be appreciated that this cannot be taken as an index of age of onset, as several children at least had previously attended other hospitals, private scientifically trained physicians or Ayurvedic healers.

\section{Sex Incidence}

As noted in the Indian Council of Medical Research report (1955), a number of workers have 
remarked on a higher incidence in male children, while others found no difference in sex distribution (Achar and Raju, 1951, quoted by the Indian Council of Medical Research, 1955). In the present group, seven children were girls $(47 \%)$, while the remainder $(53 \%)$ were boys.

Family History. It has often been noted that more than one sibling in a family may be affected, and estimates of the frequency of familial incidence vary from about 20 to $40 \%$. In the present group, only one child $(7 \%)$ had a family history suggestive of fatal cirrhosis in an older sibling.

Signs and Symptoms. All patients had a slow and insidious onset, which is in agreement with the literature. In no instance was this abrupt as in acute veno-occlusive disease, and there was never any preceding history of jaundice. Parents of affected children reported that the illness had begun with the gradual onset, over periods varying from 4 months to 3 years, of the following clinical features: abdominal enlargement in two children $(13 \%)$, general ill-health and lassitude in

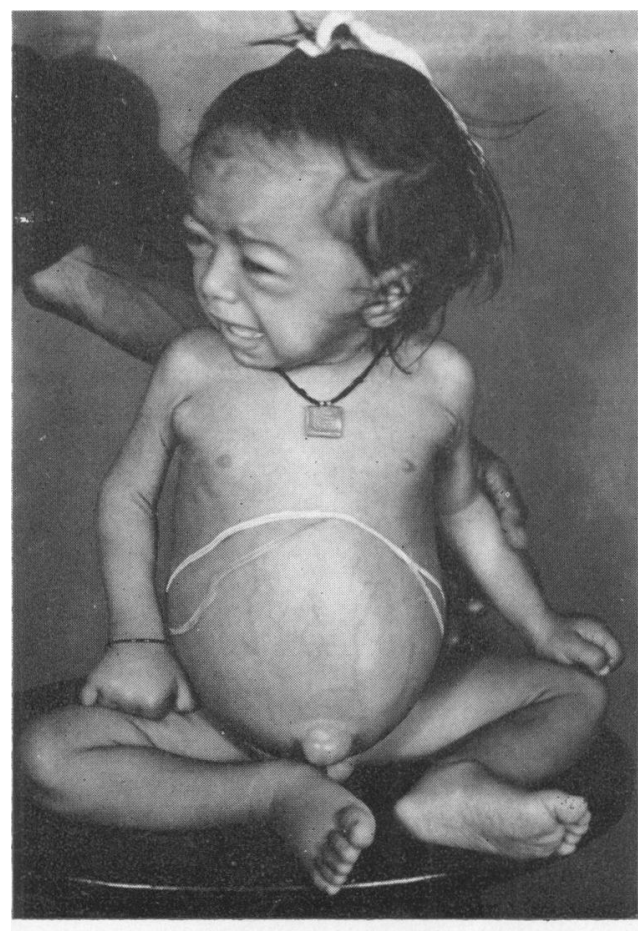

FIG. 5.

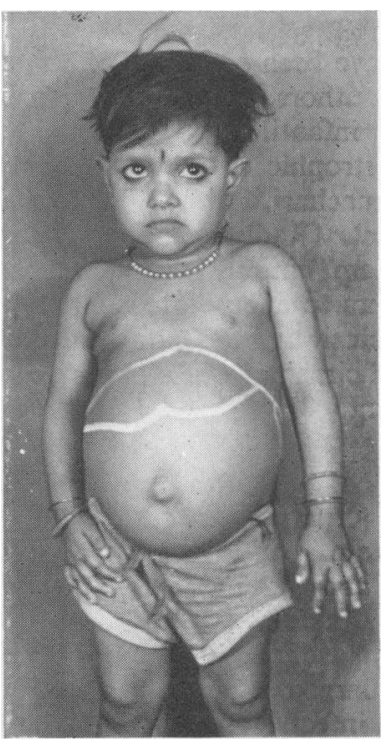

-FIG.4.-Indian cirrhosis of childhood in a Bengali girl, early in the stage of clinical cirrhosis, showing hepatomegaly, dilated collateral circulation and splenomegaly.

FIG.5.-Indian cirrhosis of childhood in a Bengali girl late in the stage of clinical cirrhosis showing cachexia, hard hepatomegaly, ascites, marked collateral circulation and splenomegaly.

two $(13 \%)$, vague upper abdominal discomfort in four $(27 \%)$, poor appetite in five $(33 \%)$, loss of weight in eight $(54 \%)$, loose stools in six $(40 \%)$ and dimness of vision in one child $(7 \%)$.

features in addition to a firm to hard hepatomegaly: splenic enlargement in eight children (54\%), ascites, varying from just detectable to tense distension of the whole abdomen in eight ( $54 \%$ ), a conspicuous collateral circulation in seven $(47 \%)$, jaundice in eight $(54 \%)$, clubbing of the fingers in two $(13 \%)$ and oedema in one child ( $7 \%$ ) (Figs. 4 and 5). In addition the following general features were noted: probable malnutrition (as evidenced by stunting, poor muscle tone) in six children $(40 \%)$, obvious of muscles and subcutaneous fat in six , clinical anaemia in five $(33 \%)$, rachitic (13), follicular keratosis in two (13), Bitot's spots in one $(7 \%)$ and bleeding gums

Laboratory Data. The following average results were obtained for the 11 children who were admitted to hospital : Haemoglobin $9 \cdot 3 \mathrm{~g}$. per $100 \mathrm{ml}$. (range $6 \cdot 9$ to $11 \cdot 6$ ); blood films for malarial parasites negative in all cases; Rhesus factor positive in five children tested; Wassermann reaction negative in all cases. A white blood count gave 11,000 per c.mm. (range 8 to 16,000 ), neutrophils $64 \%$ (range 50 to $74 \%$ ); plasma proteins (total) $6.0 \mathrm{~g}$. per $100 \mathrm{ml}$. (range 4.5 to $7 \cdot 5$ ); albumin 2.8 g. per $100 \mathrm{ml}$. (range $1 \cdot 8$ to $3 \cdot 8$ ), globulin $4.0 \mathrm{~g}$. per $100 \mathrm{ml}$. (range 2.0 to $5 \cdot 2)$. The following liver function tests were carried out: serum bilirubin, thymol turbidity, alkaline phosphatase, gamma globulin, serum cholinesterase. Abnormal results were found in at least one of these in each case, but no definite pattern emerged, except that advanced cases showed a definitely raised serum bilirubin level.

Helminth ova were present in the stools of nine children (hookworm four, roundworm three and both, two). 
Course. The 11 children admitted to the ward were treated with a high-protein-high-vitamin diet, with added polyvitamin capsules. Associated infections were dealt with, if present, and ascites tapped, if needed. No other specific treatment was attempted.

The following results were obtained with treatment periods of from four to 10 weeks in these 11 clear-cut cases of cirrhosis: slightly improved generally (with no obvious effect on hepatic condition (four), no change (one), deterioration and taken home (three), died in hospital (three) (two in cholaemia and one with bronchopneumonia). Cases could not be followed up in the Out-patient Department or at home.

Socio-economic Background. This was considered as follows:

(1) Place of Residence. According to the parents, the majority $(66.6 \%)$ of the children had always lived in Calcutta City. Of the other five, three lived in adjacent rural West Bengal, while two had recently come from Amritsar, East Punjab, and Lucknow, Uttar Pradesh, respectively.

(2) ReLigion AND CASTE. Twelve of the 15 children $(80 \%)$ were Hindus, while two were Muslims and one was a Sikh. Of the Hindus, four were Brahmins and the remaining eight were of non-Brahmin castes.

(3) Economic Status. This was very difficult to ascertain with any precision and even harder to define. However, three came of what can be called 'lower middle class' families, that is, with fathers working as clerks, small shop owners, etc. The majority were from lower socio-economic groups, such as vegetable sellers, unemployed, bidi (local cigarette makers), doorkeepers, etc. None, it must be stressed, came from the most abjectly impoverished bustee (slum) dwellers.

(4) DiET. Dietetic histories varied greatly and were never obtained with any degree of accuracy. Affected children were usually being fed on breast milk (up to about 2 to 3 years), a very little diluted cow's milk, some rice or barley, dhal (legumes) and occasionally fish. Older children were receiving some of the family masala (curry sauce). Depending upon the parents' financial status, goat's milk or dried powdered milk might also be added, although sometimes all milk might have been stopped in a mistaken attempt at dietetic treatment. Basically, then, the diet consisted of small quantities of milk together with mainly carbohydrate foods.

(5) Toxic FActors. Enquiries were made to ascertain if any of the children had been receiving possibly toxic herbal remedies, and the use of Ayurvedic* medicines before the illness was admitted by six parents $(40 \%)$, although no child was reported to have been given castor oil. Antecedent febrile illnesses were inquired about, in view of the possibility of the toxin of an infectious disease being aetiologically involved. In only one child was there a history of 'measles' just before the probable date of onset of the hepatic disorder.

Morbid Anatomy. Histological examination was undertaken in six of the total of 15 cases, four by liver biopsy and two following 'local' post-mortem examinations.

Results are summarized in the Table, and, as will be noted, the histology was similar to that seen in chronic veno-occlusive disease in all cases, especially in Nos. 3 to 6.

TABLE

SUMMARY OF MAIN HISTOLOGICAL FINDINGS IN SIX CASES OF INDIAN CHILDHOOD CIRRHOSIS

\begin{tabular}{l|l|l}
\hline Case No. & \multicolumn{1}{|c|}{ Source } & \multicolumn{1}{|c}{ Main Histological Findings } \\
\hline XS/55/54 & Needle biopsy & $\begin{array}{l}\text { Advanced cirrhosis involving portal } \\
\text { triads and branches of hepatic veins. }\end{array}$ \\
$\mathrm{XS} / 55 / 149$ & Needle biopsy & $\begin{array}{l}\text { Advanced cirrhosis, apparently in- } \\
\text { volving portal triads and branches of } \\
\text { hepatic veins. } \\
\text { Marked fibrosis showing veno-occlu- } \\
\text { sion of branches of hepatic veins. }\end{array}$ \\
$\mathrm{XS} / 55 / 151$ & Needle biopsy & $\begin{array}{l}\text { Fibrosis, apparently involving } \\
\text { branches of hepatic veins. }\end{array}$ \\
$\mathrm{XS} / 56 / 103 *$ & Necropsy & $\begin{array}{l}\text { Advanced cirrhosis with marked } \\
\text { veno-occlusion of branches of hepatic } \\
\text { veins. }\end{array}$ \\
$\mathrm{XS} / 56 / 236$ & Necropsy & $\begin{array}{l}\text { Fibrosis mainly centrilobular and } \\
\text { involving hepatic veins with thickened } \\
\text { walls. }\end{array}$ \\
\hline
\end{tabular}

* Case of Manik Das-full details given in text.

Typical Case Summary

Clinical History. Manik Das (XS/55/54), a Bengali boy, aged 3 years 9 months, was admitted with an eightmonth history of the gradual onset of abdominal swelling, 'low fever' and general ill health. He had always lived in Calcutta and was a Hindu of the Sudra caste. The boy's father owned a small shop, allegedly earning R.150 ( $£ 11.5$ or $\$ 32.20)$ monthly. There was no history of antecedent illness, and no Ayurvedic medicines or other herbals were stated to have been given. There had been two female siblings: one, aged 7 years, was alive and well, while the other was reported to have died six years previously of 'liver' when aged 4 years. Details of the past diet could not be obtained. The present diet consisted of a little breast milk, cow's milk $\frac{1}{2}$ seer

* Ayurveda ('health from the Vedas') is the traditional indigenous system of medicine employed in India. A wide variety of predominantly herbal remedies are used. 
(16 ounces) daily, together with a little barley, rice and fish occasionally.

Examination showed a thin. chronically ill boy with ascites, moderate jaundice and some dilated veins running upwards across the epigastrium. The liver was enlarged $5 \mathrm{~cm}$. below the costal margin, and was hard and not grossly irregular. There was no clubbing. The spleen was enlarged $2 \mathrm{~cm}$. Follicular keratosis was present on the elbows, while the tongue showed superficial ulceration.

Laboratory Investigations. Haemoglobin was $9 \cdot 3 \mathrm{~g}$. per $100 \mathrm{ml}$.; the white blood count 13,000 per c.mm. (neutrophils $58 \%$, lymphocytes $37 \%$ ). The Wassermann reaction was negative. Plasma proteins were $4 \cdot 5 \mathrm{~g}$. per $100 \mathrm{ml}$. (albumin $1 \cdot 5$, globulin $3 \cdot 0$ ). A blood film for malaria parasites was negative. The child was $\mathrm{Rh}$ positive. The stools showed no ova or parasites.

Course. The subsequent course in hospital was rapidly downhill and the child died 10 days after admission. Permission for a partial necropsy was obtained.

Necropsy Findings. The peritoneal cavity was found to be filled with slightly bile-stained fluid, and the whole liver was removed. The liver was finely nodular over the entire surface (Fig. 6) and the cut section showed fibrous septa and was slightly greenish.

The histological examination showed advanced cirrhosis with much fibrosis present in the form of septa causing pseudo-lobulation, but also there was a considerable increase of connective tissue inside the pseudolobules; while, in addition. there were further dense areas of fibrosis throughout the liver. The dense areas of fibrosis and the fibrous septa included portal triads as well as hepatic veins. The pseudo-lobules showed regeneration of liver cells as evidenced by liver cell cords of two or more cell layers in thickness.

There was much eosinophilic degeneration of the cytoplasm of the liver cells, many of which were seen to be disintegrating and polymorphonuclear leucocytes in varying number were present in such areas (Fig. 7). The liver cell nuclei showed polyploidy. The larger bile ducts in the portal triads were unaffected, while there was much proliferation of smaller bile ducts in the liver lobules in the areas of fibrosis. Some of these proliferated bile Jucts contained bile. The interstitial tissue showed many cells, mainly polymorphonuclear leucocytes and lymphocytes (Fig. 8). The bile capillaries between the liver cells were clearly visible and occasionally markedly dilated.

The hepatic artery and portal veins showed no changes, but many of the hepatic veins were partially cr completely occluded by subendothelial connective tissue formation (Figs. 9, 10, 11).

In comparing the appearance with chronic venoocclusive disease, it can be said that the hepatic venous occlusion is about equal in extent, but that in chronic condition in Jamaica there is usually less involvement of the portal tracts. The histological picture, such as found in Fig. 12, obtained from a case of chronic veno-occlusive disease in a Jamaican child, and leaving many portal tracts free, cannot be matched in this liver. In veno-occlusive disease there is no marked bile duct proliferation such as here, while inflammatory cells are not pronounced. This condition, as initially described by Gibbons (1888), was indeed marked in this case.

Comparison with Cases Reported in the Literature Onset. As noted earlier, all 15 cases in the present small series gave a history of gradual, insidious onset and progressive course, and this is in agreement with all previous accounts, although it is of interest to note that Achar and Chacko (1954) found that a quarter of a large group of cases in Madras were preceded by an attack of jaundice.

It is difficult to compare ages of the present cases with other reports, as it is sometimes not clear whether the ages recorded refer to the onset of symptoms or to attendance at hospital, quite apart from such well-known difficulties as inaccuracies and approximations in the figures given by the parents. However, according to the I.C.M.R. report (1955), the majority of reported cases have been between 1 and 3 years of age, so that the present group seem to be somewhat older than is usual.

Signs and Symptoms. In the literature cirrhosis in Indian children is classically considered as having three clinical stages: (1) Early (or stage of onset), (2) intermediate, (3) late. These have been termed precirrhotic, compensated and decompensated cirrhosis by Chatterjee (1940).

For the first or early stage, descriptions are extremely vague and non-committal, and vary considerably according to different authorities. Clinical features considered to be attributable to this stage of the disease are such protean ones as general ill-health and lassitude, altered appetite (either anorexia or increased), constipation or diarrhoea, low or occasional fever, flatulence and minor abdominal distension. According to some, the liver is just palpable, while the stools may be pale.

In the second or intermediate stage, children are alleged to be peevish and irritable, and to have protuberant abdomens, livers definitely enlarged with a sharp, 'leafy' edge, together with some splenomegaly and dilated superficial abdominal veins. Ascites and some ankle oedema may be present, while the sclera are subicteric and the stools pale.

In the third or final stage, the picture is that of clinically obvious cirrhosis. The child is wasted, usually icteric and with a prominent abdomen, due 


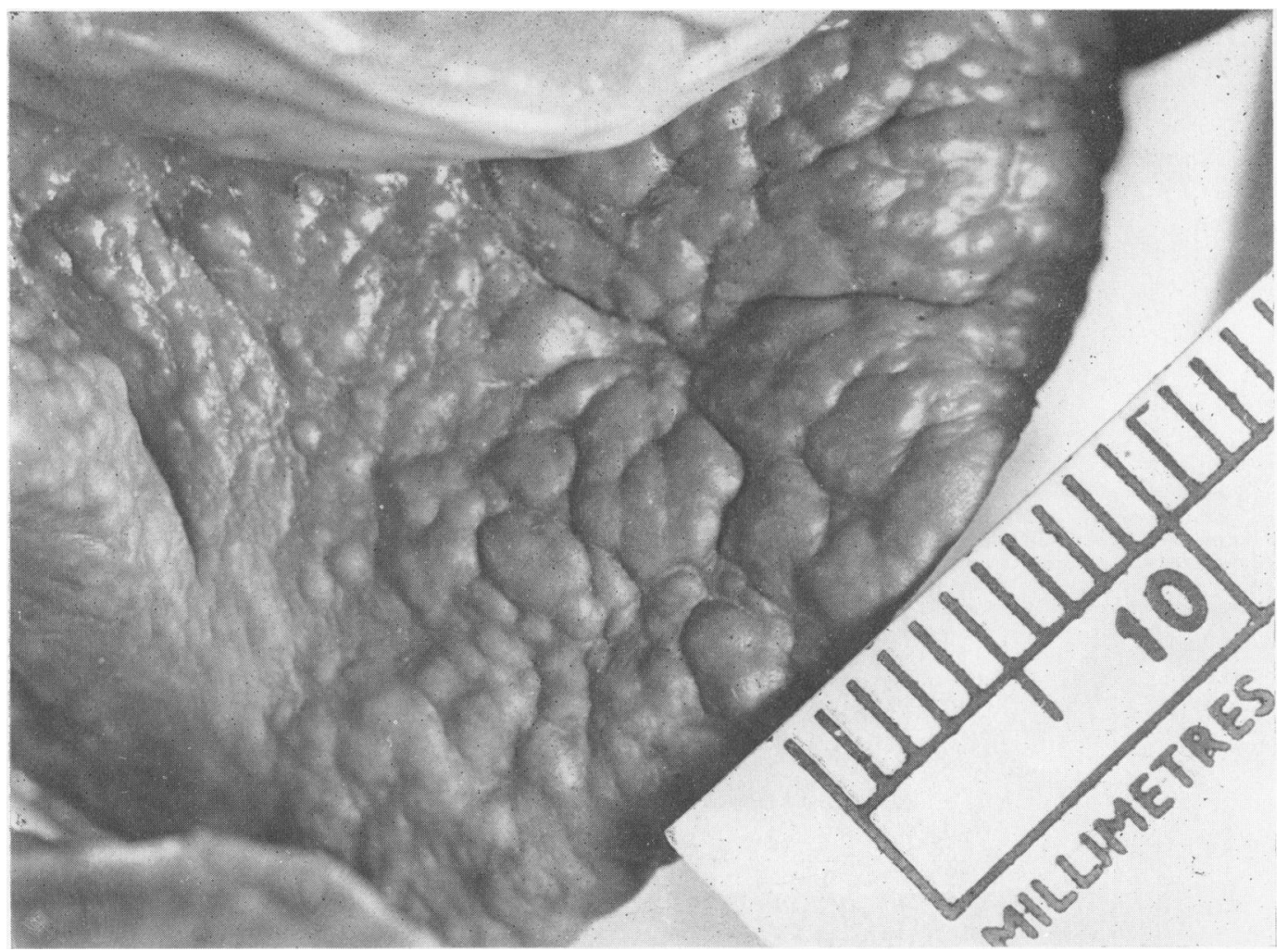

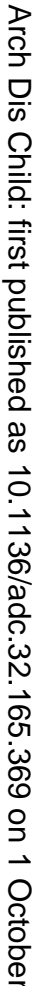

Fig. 6.-Picture of liver at necropsy in a case of Indian cirrhosis of childhood showing a finely nodular surface (Manik Das).

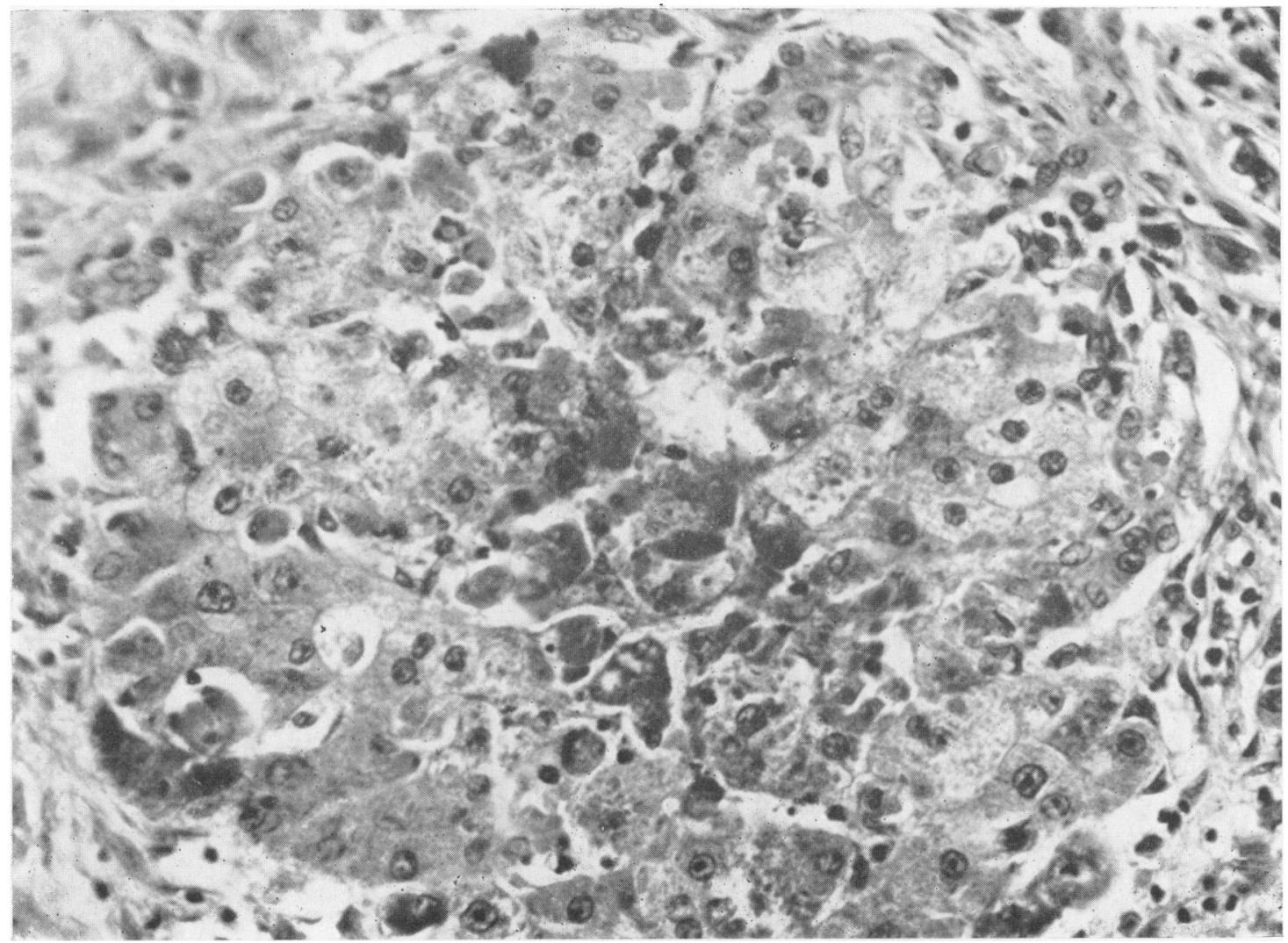


FIG. 8.- Liver showing bile duct proliferation with 'thrombus' in the bile duct at arrow, and marked infiltration with polymorphonuclear leucocytes and lymphocytes in the intestinal tissues (Manik Das). Haematoxylin and eosin $\times 450$.
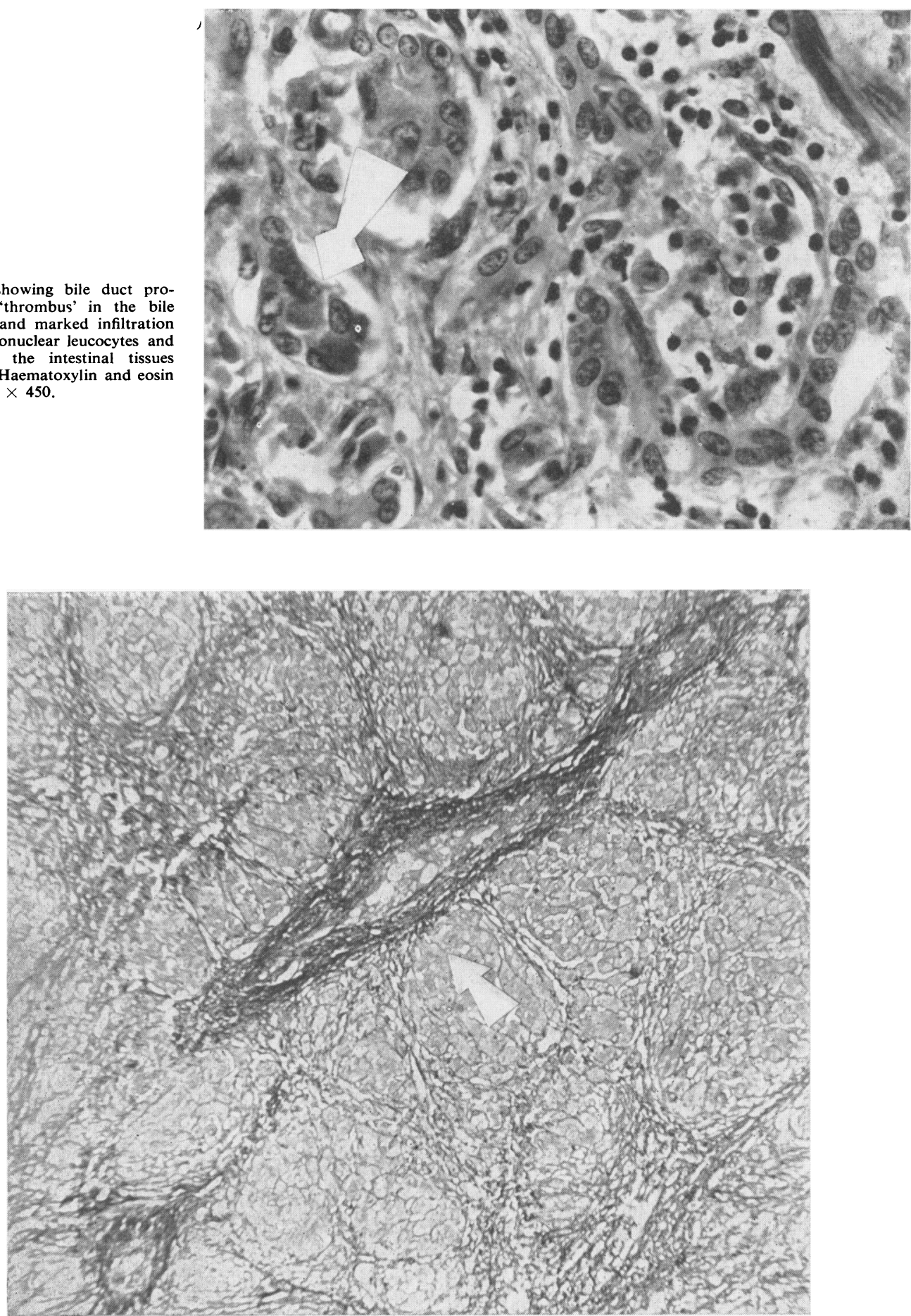

FIG. 9.-Occlusion of branches of the hepatic vein (Manik Das). Reticulin $\times 60$. 


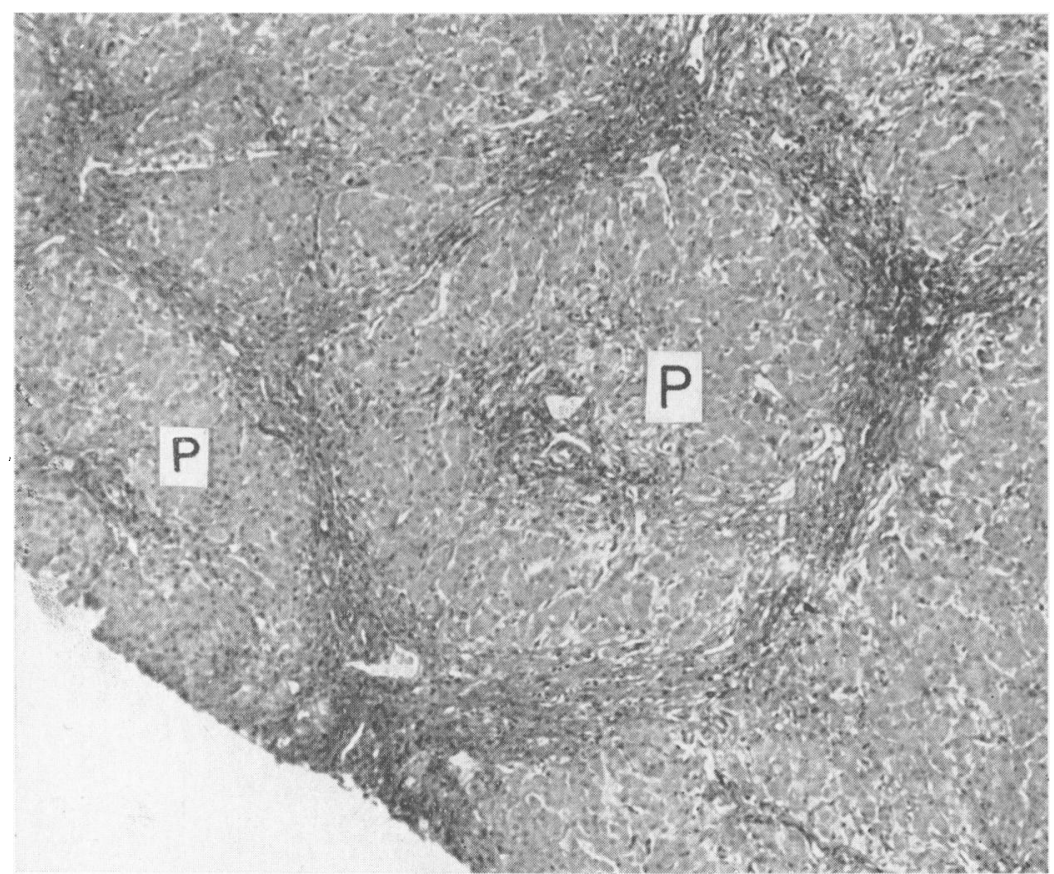

Fig. 12.-Jamaican child with chronic V.O.D. in whom the liver showed non-portal cirrhosis.

to ascites, smooth or finely irregular, hard hepatomegaly and, usually, definite splenomegaly. Marked engorgement of the collateral circulation will be visible. The urine will be scanty, and may contain albumin, bile pigments and salts.

Two-Stage Classification. In view of the apparent present confusion and lack of specificity of alleged early features (i.e., general ill-health, flatulence, pale-coloured stools, etc.), many of which can be seen in a percentage of Indian children attending paediatric out-patient or child welfare clinics, the following 'two-stage' classification is suggested tentatively as a practical, more easily definable and standardized system of identification, at least until further knowledge of the natural history of the disease is acquired. It must be stressed that these two stages overlap and merge into one another.

(i) Stage of Hepatomegaly. It is generally agreed that the most suggestive clinical sign, both early and late, is a firm or hard, painless enlargement of the liver, coming on insidiously, and in India, young children, especially in the first five years of life, should be suspected of having early cirrhosis, if other causes of hepatic enlargement-such as malaria, kala azar, kwashiorkor, congenital syphilis and congenital lesions of the bile ducts - can be excluded. (It is realized that at present there is no proof that all cases pass through a stage of hepatomegaly early in their evolution to frank cirrhosis. Nevertheless, this concept of a stage of hepatomegaly, based on the consensus of practical experience and clinical evidence, may be used at least temporarily until the acquisition of newer knowledge permits of more specific diagnostic criteria.)

In addition, the physiologically palpable soft liver found in many young children in the first few years of life, especially if exaggerated by chest deformities such as occur in rickets, will have to be borne in mind as will the transient soft hepatomegaly which is considered by some to occur as a temporary phenomenon in young children during any acute febrile illness. The acute tender liver of amoebic hepatic involvement can be mentioned, but should present no diagnostic problem.

The diagnosis of probable early I.C.C. depends, therefore, as judged by present knowledge, simply on finding a definite firm or hard hepatomegaly for which no other explanation can be discovered. Other variable and apparently entirely non-specific features may be present, such as general ill-health, low fever, etc. Chaudhuri (1944) says that there may be complaints of a general nature vaguely referable to the digestive system.

Clinical diagnosis at this stage can only be presumptive until the development months later of definite cirrhotic features. A positive family history 
is suggestive, but gives no scientific proof. Specific laboratory biochemical tests do not at present exist. Liver biopsy would appear ultimately to offer the best possibility of early diagnosis, but much further work is needed to investigate the histopathology of what may well be a heterogenous group and especially to delineate the specific changes of early I.C.C.- - a difficulty increased by present incomplete knowledge of the morbid anatomy of the liver of normal, but undernourished, Indian children. In the specimens discussed in the I.C.M.R. report (1955), initial changes consisted of patchy, but fairly widespread, degeneration of liver cells, associated with mild reactive change in and around Glisson's capsule and in the sinusoids. However, as this Committee themselves imply, these findings cannot be accepted as universally applicable as definite histological criteria suitable for use in early diagnosis.

The difficulty of making a diagnosis on clinical grounds alone is clearly shown, when, in the early stages of the present investigation, five children with moderate firm hepatomegaly were found, at least in the small fragment of liver available following needle biopsy, to have apparently normal histology (four) and moderate fatty change (one). Similarly, as noted in the I.C.M.R. Report (1955), a number of children in Achar's large-scale investigation in Madras in South India were found to show no abnormality at liver biopsy, despite their having what were considered to be abnormal palpable livers.

(ii) Stage of Clinical Cirrhosis. At this stage, a diagnosis is usually relatively simple on clinical grounds. All the children in the present small series of 15 fell into this category. Affected children show a hard, smooth or finely granular enlargement of the liver, together with some or all of the following features of hepatic disease: ascites, icterus, splenomegaly, dilated collateral circulation. Loss of weight and anaemia are usual. Ankle oedema is not uncommon. The stools are clay-coloured and the urine is dark, containing bile pigments and salts, and, occasionally, albumin. Moderate intermittent fever is usual. Laboratory tests have not been sufficiently investigated, but a raised serum bilirubin level, some degree of anaemia and a variable pattern of abnormal liver function tests are seen. Leucocytosis is often present, but may well be rather related to intercurrent infection, especially of the respiratory tract. The histology of the liver, as shown by biopsy and at necropsy, is that of a diffuse fibrosis, details of which will be given later.

As to differential diagnosis, other forms of cirrhosis must be excluded, including those associated with congenital syphilis, Rhesus incompatibility, post-hepatitic scarring, and, in young infants, congenital atresia of the bile ducts. These can usually be excluded by the history and laboratory investigations.

In West Bengal, Cooley's anaemia presenting with jaundice and hepato-splenomegaly can be differentiated by the marked anaemia, characteristic skull shape, and other haematological investigations.

Socio-economic Background. This was considered under specific headings:

(1) Geographical Incidence. According to the available medical literature, I.C.C. has only been reported from India, with the exception of the few cases described from Colombo, Ceylon, by Karunaratne (1951) and by Fernando (1954). Within India, the disease has been reported from all States, with the apparent exceptions of the East Punjab and Pepsu. The condition has always been most commonly recorded in Madras and West Bengal, especially Calcutta. It is of interest-and may be of aetiological significance - that this type of childhood cirrhosis does not seem to have been described from other parts of south-east Asia.

Information regarding the public health significance of I.C.C. is meagre. No statistics are available summarizing the incidence of the disease in the population as a whole in any part of the country. As the I.C.M.R. report (1955) observes, most series have been from quite unrepresentative population samples, that is, from hospitals in large towns. There appears at the moment to be an impression amongst some experienced clinicians in larger Indian cities that the condition is seen less frequently nowadays than it was 15 years ago.

(2) Religion and Caste. As has been stressed by all observers, the disease occurs most commonly in Hindus, often of the Brahmin caste. However, it must be realized that Hindus form the vast majority in most areas of India. That I.C.C. occurs amongst non-Brahmins is clearly shown by even the present small series where eight were so classified. Similarly other workers have shown that the condition does affect Muslims, Anglo-Indians and other minority groups. The I.C.M.R. (1955) summarizes the situation accurately when it says : 'It is impossible to say on the basis of available information whether the observed predominance among the Hindus is merely a reflection of their numerical superiority in the country or whether they are more susceptible to the disease than others.'

(3) Economic Status. It has long been remarked that I.C.C. does not primarily affect the very lowest 
and most impoverished socio-economic groups, as does kwashiorkor, for example. As Prabhu (1940) rightly observes: 'Curiously enough, the poorest classes seem to be exempt from it. It is hardly ever found among sweepers, rickshaw-pullers, labourers or in vagrant classes or in slum areas, among whom diseases attributable to malnutrition are found.'

While this was certainly so in the present small series, as the I.C.M.R. (1955) report stresses, this does not necessarily mean that malnutrition plays no part in the aetiology, 'for it is well known that the diet of some of the middle and even upper classes may be unbalanced and qualitatively unsound, although quantitatively adequate'. (In Calcutta this was certainly observed to be correct in another context, in that rickets was found to occur much more commonly amongst the children of strictly vegetarian Marwari merchants of considerable wealth.)

Morbid Anatomy. Despite the recent increased interest in the pathology of I.C.C. and the consequent intensification of active research, comparatively few necropsies have been reported, probably not more than 40 in all, and these have all been in advanced cases dying in the final phases of the stage of clinical cirrhosis. Thus, Bhende and Deoras (1954) stress that the records of only nine necropsies were available to them from the period 1926 to 1954 , in the archives of a leading hospital in Madras.

All accounts are in general agreement as to the gross appearance of the liver in advanced cases that come to necropsy.

'The organ is usually shrunken, stained green with bile, of normal shape with sharp margins and firm consistency. The capsule is thick and somewhat opaque white in colour and free from adhesions or exudation. The capsular surface may be either smooth with indistinct lobular markings, or may be uneven, granular or flatly nodular, particularly on the under-surface. The sectioned surface is greenish in colour with obliteration of the normal lobular pattern by a diffuse fibrosis. It presents either a smooth greyish-green surface finely mottled with small scattered dark-green areas or a finely granular surface with a diffusely spread greyish-green fibrous network enclosing small rounded islands of regenerating parenchyma' (I.C.M.R., 1955).

Gibbons (1888) compared the bile-stained areas of regenerating hepatic tissue to 'mustard seed granules'; while the surface of the liver has been considered to have a 'morocco leather' appearance.

Findings at the two partial necropsies in the present series agreed completely with this general naked-eye description. A comparison of the histological changes found at necropsy and at liver biopsy in the present cases and by other workers is made later in this paper, when these are also compared with the morbid anatomical findings of veno-occlusive disease in Jamaican children.

Treatment and Course. There is general agreement that the prognosis of I.C.C., in what has here been termed the stage of clinical cirrhosis, is usually hopeless, in that, after a period of months, or even a few years, deterioration occurs and death results from cholaemia, secondary infection, or, less commonly, oesophageal haemorrhage. The situation does not seem to have altered since 1890 when Sen (quoted by Krishna Rao, 1950) noted that the established disease was 'more certain of its victims than the dreaded cholera or smallpox'.

A large number of different, often bizarre forms of treatment, usually based on a particular worker's theoretical concept of the aetiology, have been tried at various times and cures claimed. Inspection of such claims invariably shows a lack of precise criteria for initial diagnosis, absence of control cases, inadequate follow-up and small numbers of cases. Many children allegedly cured may not have been suffering from the condition at all. The I.C.M.R. report again accurately summarizes the situation: 'No convincing evidence has so far been produced to show that the natural course of the disease is in any way modified by the several régimes which have been advocated enthusiastically from time to time.'

One difficulty, at least in West Bengal amongst 'lower middle class' parents, is the fact that there is a wide awareness of cirrhosis as a serious, often fatal childhood disease - often known locally by the English word 'liver'. The anxiety of parents of this type provides a fertile field for quacks and for widely advertised proprietary and Ayurvedic 'liver cures', such as those containing extract of Kalmej (Andrographus paniculata).

Not infrequently 'liver' is diagnosed in Bengali children on the basis of such common and nonspecific features as lassitude, fairly loose, rather pale stools and slight fever, together with physiologically palpable liver in a flabby, somewhat anaemic child.

In view of the present ignorance of the cause of I.C.C., therapy is empirical with a high-protein, highvitamin diet, together with plenty of added sugar and supplementary polyvitamins, and the treatment of associated infection. Terminally, protein should be reduced, in view of the known toxic effect on the central nervous system in cases of liver damage of protein breakdown products (Sherlock, Summerskill, White and Phear, 1954).

When considering the present-day treatment of I.C.C., and especially some of the complex régimes that have from time to time been advocated, it is 
perhaps salutary to consider the original form of therapy advocated by Sen (1887): 'Muriate of ammonia, iodide of potassium, nitro-hydrochloric acid, taraxacum, ipecacuanha and rhubarb in a mild bitter infusion were administered internally, while small mustard plasters, iodine ointment, tincture of iodine and nitro-hydrochloric acid baths were used externally.'

\section{INDIAN CHILDHOOD CIRRHOSIS AND VENO- OCCLUSIVE DISEASE OF THE LIVER COM- PARED}

\section{Clinical Picture}

The clinical picture of veno-occlusive disease of the liver as seen in Jamaican children and that of Indian childhood cirrhosis present many similarities and certain apparent differences.

\section{Economic Status}

In both conditions, affected children do not come from the very lowest socio-economic groups. However, in India, it is well known that cases also occur in 'upper middle class' families as, for example, where the father is a physician or merchant. This is unknown in Jamaica.

\section{Diet and Nutrition}

Apart from the study by Rhodes (1952) in Jamaica, when she found that affected children were having a diet low in protein, detailed dietetic investigations do not appear to have been carried out on either group. However, in both conditions it is probable that the diet is usually inadequate, and that this is reflected in the children's nutritional status. In the early stages of both diseases, children are usually undernourished without showing evidence of gross malnutrition, while in the final cirrhotic stage, cachexia develops as a result of the chronic illness.

\section{Onset and Clinical Features}

Jamaican children first presenting with either the subacute or chronic stages of veno-occlusive disease very much resemble the usual picture of I.C.C. They are usually brought in by parents with complaints of abdominal swelling, due to ascites and/or an enlarged liver. Following this, both groups show the same progressive downhill course over months or years, sometimes with long clinically latent periods, but eventually terminating fatally in cholaemia, oesophageal haemorrhage or intercurrent infection.

Personal experience and descriptions in the medical literature give the impression that both early marked dilatation of the collateral circulation and haemorrhage from oesophageal varices are commoner in veno-occlusive disease, while jaundice seems to occur earlier and in a higher percentage. In addition, Indian children with childhood cirrhosis are reported to show more general features of illhealth, such as loose stools, poor appetite, etc.

An important difference between veno-occlusive disease in Jamaica and I.C.C. is that cases of the former may present as acute veno-occlusive disease, that is, with an initial acute episode of hepatomegaly and ascites, during which the histological picture of acute exudative subendothelial thickening of small and medium sized branches of the hepatic veins can be found in liver biopsy material. In addition, a number of cases of veno-occlusive disease presenting in the subacute or chronic stage have a past history suggestive of a possible acute episode of hepatic veno-occlusion. As far as can be discovered by perusal of the literature, by discussion with experienced clinicians and as a result of personal observation, this type of initial acute episode has never been reported from India.

If the ages of onset of cases of Jamaican venoocclusive disease presenting in the subacute or chronic stages are compared with the present series, it will be seen that the range is very similar, that is, from about 1 to 9 years. However, in most accounts of I.C.C. the main incidence is given as between 1 and 3 years, so that most evidence points towards the Indian variety of cirrhosis usually manifesting itself some two or three years earlier than is customary in Jamaican cases. Finally, as a point of similarity, both conditions may often show a familial incidence.

\section{TROPICAL CHILDHOOD CIRRHOSIS IN OTHER AREAS}

Although not as commonly reported, nor, apparently, such a public health problem as in Jamaica and India, cirrhosis of childhood has also been the subject of investigation in certain other tropical regions.

In Egypt, where cirrhosis in children and adults is usually considered to be mainly the result of combined malnutrition and schistosomiasis, Hashem (1948) has also described what he terms 'a variant of subacute portal cirrhosis encountered in Egyptian children', which is unrelated to bilharzial infection. This condition, which occurs mainly in children between the ages of 8 months and 7 years, is of unknown aetiology. The main clinical features appear to be the fairly rapid onset of cirrhosis, with a very enlarged, firm liver and dilated, tortuous thoraco-abdominal veins. Oedema of the lower limbs is a frequent finding, and the spleen is enlarged 
in one-third of cases. Haematemesis is not reported. The syndrome is of especial interest as, as will be noted later, the liver histology very much resembles that of veno-occlusive disease.

Walters and Waterlow (1954) have reported an important and broad-based investigation into the pathogenesis of hepatic fibrosis in African children and young adults in the Gambia. In these cases, the main features appear to be general ill health, distended abdomens and ascites. Jaundice was unusual, and dilated collateral circulation and haematemesis were not noted. Anaemia was often a conspicuous feature. No history of previous acute episodes was mentioned.

\section{HISTOLOGICAL FINDINGS}

Radhakrishna Rao $(1935,1954)$ described histological studies in I.C.C. when widespread obliterative lesions of the smaller divisions of the hepatic venous tree were found and appeared to be playing an important part in the evolution of the cirrhosis. Of the many articles from India, it has become evident that histological study of I.C.C. has been relatively limited because of the difficulty of obtaining necropsy and other material. Bhende and Deoras (1954) summarized the various reports on the pathological findings as follows. Necrosis of liver cells uniformly distributed throughout the organ, but varying in degree in different areas, has been observed by most writers. Fibrous bands, as well as diffuse fibrosis throughout the liver, have been reported; this fibrosis includes portal triads, but, according to some writers, may also originate from and include branches of the hepatic vein which may or may not show thickening of their walls and/or obliteration of their lumina. Dr. Y. M. Bhende of Madras has kindly allowed us to study again the histology of seven of his cases and we confirm his findings that, in several of the sections, there is very marked obliteration of the hepatic veins (Figs. 13, 14). It should be noted that, in the paper by Bhende and Deoras (1954), the nine cases examined histologically represent hospital necropsy material collected over a period of 25 years and it must have been difficult to establish that these children did, in fact, all belong to the same clinical entity. On the whole, authors other than Radhakrishna Rao $(1935,1954)$ and Ramachandra Rao (1935) have not been much impressed by the obliteration of the branches of the hepatic veins. Nodules of regeneration have been found to be absent or not very marked. The biliary tree was reported to be normal by Radhakrishna Rao (1935, 1954), but bile duct proliferation in varying degrees was remarked by several authors. Several of the
Indian authors have felt that the histological picture of I.C.C. was that of toxic cirrhosis.

Achar and Chacko (1954) examined material from 10 necropsies and 75 liver biopsies from cases which 'clinically looked like infantile biliary cirrhosis'. They paid special attention to the hepatic venous tree and could not demonstrate any obliteration. Srivastava and Aikat (1954) studied the histology of liver biopsy specimens in 45 cases and, on the whole, confirmed the findings of earlier writers; they do not comment on the hepatic veins.

The Liver Diseases Sub-Committee (I.C.M.R., 1955) reported on a careful study of a total of 60 cases in various stages of the disease. They concluded that the basic alteration in the liver in I.C.C. is diffuse liver cell damage and replacement fibrosis. This fibrosis was portal in origin, but might go on to form bands which would then divide the liver into pseudo-lobules, while these pseudolobules would in their turn be invaded by fibrous tissue. In other cases, the fibrosis remained diffuse without any attempt at pseudo-lobulation. Occlusion of the hepatic veins was not a feature.

Fernando (1954) describes eight cases with the clinical picture of I.C.C. from Ceylon. The histological appearances were those of intralobular cholangiolitic biliary cirrhosis. Karunaratne (1951) had earlier reported three cases observed in Ceylon and concluded that fibrosis did not originate in the portal tracts.

From Egypt, Hashem (1939) reported a special form of cirrhosis of the liver in children. Pathological findings in three cases were described: acute haemorrhagic necrosis associated with phlebitis and thrombosis of the smaller divisions of the hepatic veins was noted and was a prominent feature in the acute and subacute cases. This was followed by fibrosis and cirrhosis.

From West Africa, Walters and Waterlow (1954) have described fibrosis of the liver observed in Gambian children, of which the aetiology was unknown. The authors suggested the possibility of a dual lesion and a dual aetiology, viz., (a) a nutritional or metabolic lesion of the parenchyma, and (b) the development of hyper-reactive mesenchymal elements as a result of malaria. A severely fatty liver characteristic of kwashiorkor was never seen, neither was there frank necrosis of parenchymal cells.

In South Africa, Higginson (1956) has recently reported that he has observed four cases of venoocclusive disease. Suckling and Campbell (1957) have reported from South Africa that the development of a cirrhosis could not be established in a five-year follow-up study of previously treated 
kwashiorkor patients. The general tendency at present is to consider that malnutrition and kwashiorkor per se are not in themselves responsible for a subsequent fibrosis or cirrhosis of the liver-a view also expressed on the basis of observations in Jamaican infants and children (Bras, 1955).

In Indonesia, Lie and Tjokronegoro (1954) found fibrosis and cirrhosis of the liver relatively frequently in children in Java with or without malignant malnutrition. The malnutrition was apparently not a factor in the production of the fibrosis. They concluded that viral hepatitis or a disease clinically consistent with virus hepatitis might be one of the causes of cirrhosis in this country. One of the present authors (G.B.) has been in the position to study some of their material and shares the opinion expressed by these authors that the histological picture also is not like that of venoocclusive disease.

Blankhart (1953) reported the relatively frequent occurrence of cirrhosis of the liver in the island of Sangir, lying to the north of Celebes. This condition was clinically diagnosed
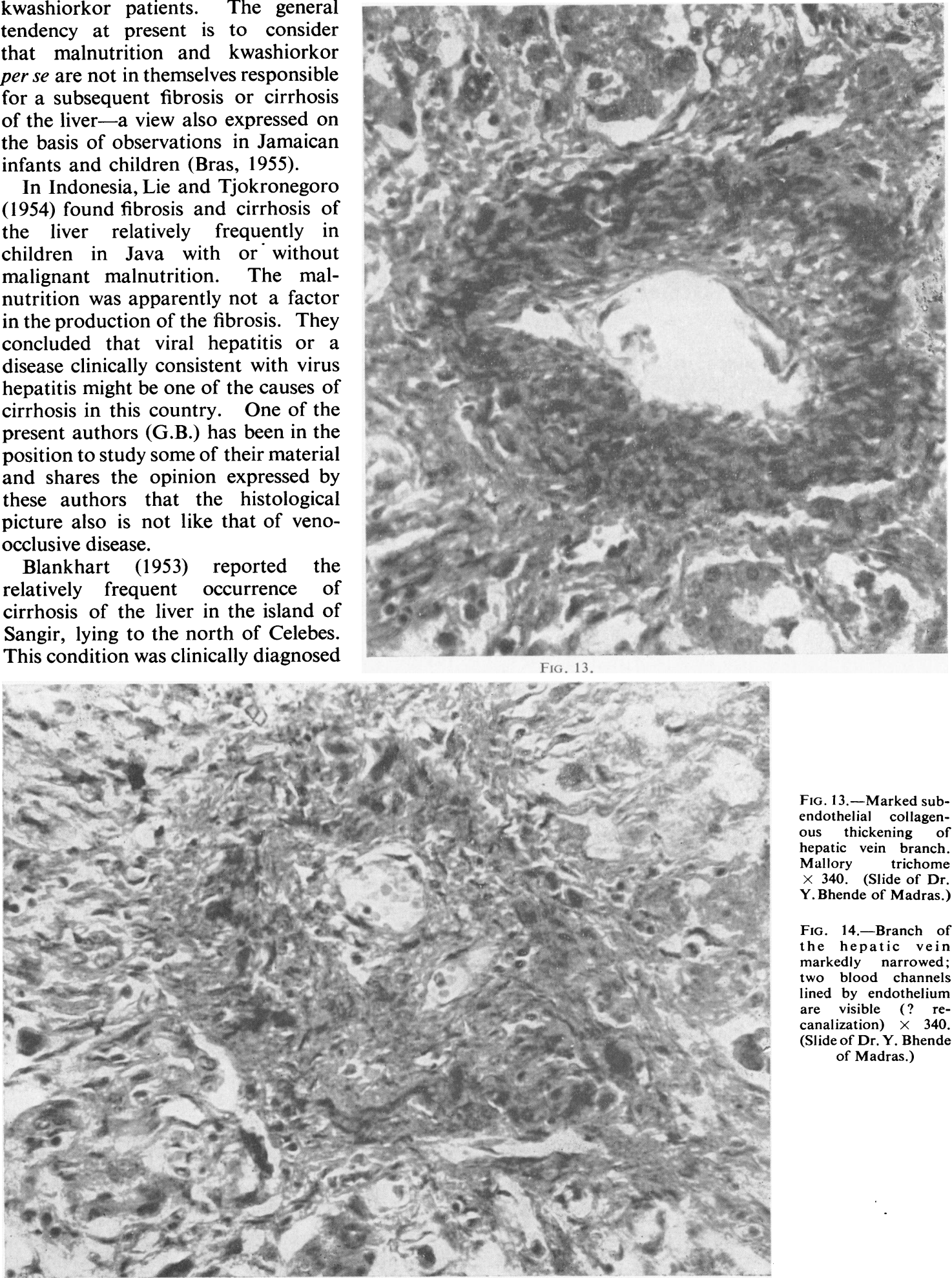

Fig. 13.-Marked subendothelial collagenous thickening of hepatic vein branch. Mallory trichome $\times 340$. (Slide of Dr. Y.Bhende of Madras.)

Fig. 14.-Branch of the hepatic vein markedly narrowed: two blood channels lined by endothelium are visible (? recanalization) $\times 340$. (Slide of Dr. Y. Bhende of Madras.) 
in 32 children under 15 years of age, but was not seen in those younger than 5 years. Histology was difficult to obtain, but whilst working in Indonesia one of the present writers (G.B.) was able to examine some of Blankhart's material. The cirrhosis seen was histologically well advanced and, although occasionally veno-occlusion of branches of the hepatic vein was observed, it could not be excluded that this was a sequel to the cirrhosis rather than a primary lesion.

From Europe, a condition of obliteration of hepatic veins, named endophlebitis hepatica obliterans, occurring in infants and children, has been reported. Wurm (1939) reported eight cases at the age of 3 months, all ending fatally. A bacterial toxic aetiology through artificial feeding was incriminated. Burkhardt (1938) saw this condition in a 2-year-old child for which he postulated an allergic cause. Konig (1943) observed the condition in a newborn child and postulated intoxication by the transplacental route.

A number of other conditions leading to occlusion of the hepatic veins have been reviewed in a previous publication (Bras et al., 1954). Various conditions of the liver giving rise to fibrosis and/or cirrhosis in children have been described, such as syphilis and the more obscure types exhaustively reviewed by Rössle (1930). More recently erythroblastosis (Craig, 1950) and fibrosis in children with acute leukaemia following folic acid antagonists (Colsky, Greenspan and Warren, 1955) have been reported. These do not at present warrant further discussion with regard to the cases reported here.

\section{DISCUSSION}

A condition in the liver, with obliteration of hepatic veins as a predominant feature, has been established beyond doubt as occurring in infants and children. The reports from Jamaica, Egypt, India, South Africa and Europe, submitted by different authors, substantiate this. In Jamaica, Egypt, South Africa, Europe and some cases from India-such as those of Rhadakrishna Rao and Ramchandra Rao, some of Bhende's and Deoras' cases, as well as the Indian children reported in the present paper-this obliteration is prominent and has been of sufficient importance to be considered by the various investigators to be responsible for the development of fibrosis and cirrhosis subsequent to the obstruction, or, at least, to have played an important role in the development of fibrosis and cirrhosis. On the other hand, there are several writers from India who have expressly denied the presence of hepatic venous lesions and it is obvious that more study is needed to clarify this point. Unlike the picture in Jamaica, I.C.C. does not appear to have the characteristic acute episode with the development of massive ascites, which separates this entity quite clearly from any other. Much of the study in I.C.C. has therefore necessarily been performed on well-established cases of cirrhosis and every histopathologist knows that in such an event a recapitulation of the morphogenesis is frequently impossible. On the basis of studies in cirrhotics in Jamaica, it is suspected that at least some of the vessels called by Indian workers patent hepatic vein branches are in fact examples of collateral circulation. Injection studies of the hepatic veins with radio-opaque material (Stuart and Bras, 1957) may assist considerably here. In addition, it is by no means certain that all the authors describing I.C.C. have indeed reported on one disease entity only, instead of on a variety of diseases which have liver damage and subsequently fibrosis in common.

It seems, however, improbable that the liver cell degeneration and necrosis so uniformly observed by all the students could in all cases be secondary to veno-occlusion. This mechanism was accepted in Jamaica for veno-occlusive disease since all cases had sufficient changes in the hepatic veins to explain the centrilobular necrosis observed, even though the Jamaican workers have always stressed the fact that hepato-cellular damage, either primary or concurrent, but independent, of the hepatic venous occlusion, cannot be excluded. It appears necessary that post-mortem vascular injection studies of the liver should be done in I.C.C.

Analogous controversial statements exist in the veterinary literature. Experimental work on poisoning with certain toxic plants (Crotalaria $s p$. and Senecio sp.) has demonstrated liver cell damage which has been extensively commented upon by some authors (Bras et al., 1957). Other authors working with the same plant species noticed changes of the hepatic veins; whilst, in South Africa, Senecio poisoning in man has been observed to produce hepato-venous occlusion (Selzer and Parker, 1951). Our own experiments on rats with Senecio and Crotalaria have produced extensive liver cell degeneration and necrosis in many animals without changes in the hepato-venous tree, while in some other animals a disease indistinguishable from human veno-occlusive disease has been produced. Lastly, Crotalaria fed to cattle in Jamaica has also resulted in veno-occlusive disease and fibrosis.

It would, therefore, appear acceptable to postulate that toxic liver damage in children may produce either liver cell degeneration and necrosis concurrent with changes in the cholangioles as described in cholangiolitic cirrhosis (Rössle, 1930; Watson and Hoffbauer, 1946), or hepato-venous changes, 
or both. This certainly appears to be the case in such experimental animals as rats, cattle, horses. Experiments are at present being conducted with the object in view of trying to separate the parenchymal toxic component from the vascular toxic component.

\section{SUMMARY}

Cirrhosis of the liver is common in children in parts of India, especially in West Bengal and Madras, and in the West Indian island of Jamaica, where it usually occurs as a late result of 'veno-occlusive disease of the liver'. The literature concerning venoocclusive disease is reviewed, with especial reference to its possible relation to the ingestion of plant toxins of certain 'bush teas', particularly species of Crotalaria and Senecio.

The clinical and pathological features of 15 cases of Indian childhood cirrhosis (I.C.C.) seen in Calcutta, West Bengal, are presented, analysed and compared with accounts in the literature. A twostage clinical classification is suggested: (1) stage of hepatomegaly, (2) stage of clinical cirrhosis. The socio-economic background of the present cases is compared with reports by previous workers.

The clinical picture and morbid anatomy of veno-occlusive disease and I.C.C., as judged by the literature and the present cases, are compared and contrasted. While some cases are clinically similar, the absence in I.C.C. of the acute episode that occurs in some children with veno-occlusive disease is stressed. Hepatic venous occlusion was found in all six of the 15 children who were liver biopsied or who came to necropsy. This histological feature has been noted by some other investigators, although more workers have stressed the presence of parenchymal damage.

It is noted that, in both experimental animals and in veterinary medicine, it has been shown that certain plant toxins may sometimes act on liver cells and sometimes on the hepatic veins. The possibility of a similarly varied response in children is suggested.

Our thanks are due to Dr. R. N. Chaudhuri Director, School of Tropical Medicine, Calcutta, and to Dr. K. V. Krishnan, Director, All-India Institute of Hygiene and Public Health, Calcutta, for their advice and cooperation; and to Dr. Y. M. Bhende for permitting us to examine liver slides from Dr. Deoras' and his collection of autopsy material.

\section{REFERENCES}

Achar, S. T. and Chacko, R. (1954). Indian J. med. Sci, 8, 442 Asprey, G. F. and Thornton, P. (1953). W. Indian med. J., 2, 233
Beaver, P. C., Snyder, C. H., Carrera, G. M., Dent, J. H. and Lafferty, J. W. (1952), Pediatrics, 9, 7 .

Bhende, Y. M. and Deoras, S. M. (1954). Indian J. med. Sci., 8, 21. Blankhart, D. M. (1953). Docum. Med. georg. trop. (Amst.), 5, 7. Brahmachari, U. and Brahmachari, P. (1938). In The British Encyclopaedia of Medical Practice, Vol. 8, p. 132. London. Quoted by Indian Council of Medical Research Report (1955).

Bras, G. R. (1955). In Protein Malnutrition. Proceedings of a Conference in Jamaica (1953), ed. Waterlow, J. C. Cambridge.

and Berry, D. M. (1956). W. Indian med. J., 5, 37.

- and György, P. (1957). In press.

and Hill, K. R. (1956). Lancet, 2, 161.

Jelliffe, D. B. and Stuart, K. L. (1954). A.M.A. Arch. Path., $57,285$.

- and Watler, D. C. (1955). W. Indian med. J., 4, 201

Burkhardt, L. (1938). Frankfurt Z. Path., 52, 567.

Chatterjee, D. (1940). Indian med. J., 34, 266.

Chaudhuri, K. C. (1944). Indian J. Pediat., 11, 61.

Colsky, J., Greenspan, E. M. and Warren, T. N. (1955). A.M.A. Arch. Path., 59, 198.

Craig, J. M. (1950). Ibid., 49, 665.

Davidson, J. (1935). J. Path. Bact., 40, 285

Fernando, P. B. (1954). J. Child. Hosp. Colombo, 3, 3.

Gibbons, J. B. (1888). Indian med. Gaz., 23, 52.

Hashem, M. (1939). J. roy. Egypt. med. Ass., 22, 319.

- (1948). Ibid., 31, 541 .

Hill, K. R., Rhodes, K., Stafford, J. L. and Aub, R. (1953). Brit. med.J., 1, 117.

Higginson, J. (1956). Proc. Kampala Conf. on Cancer of the Liver. Indian Council of Medical Research (1955). Indian J. med. Res. 43,723 .

Jelliffe, D. B., Bras, G. and Stuart, K. L. (1954a). Ann. trop. Med. Parasit., 48, 386.

,$- \frac{1}{\mathrm{~W}}$ (1954b). Pediatrics, 14, 334

Karunaratne, W. A. E. (1951). In Liver Disease: Ciba Foundation Symposium, p. 106. London.

König, J. (1943). Virchows Arch. path. Anat., 311, 527.

Krishna Rao, P. (1950). Indian med. Gaz., 85, 150.

Lahiri, S. C. (1936). Ibid., 71, 313.

Lie, K. J. and Tjokronegoro, S. (1954). Docum. Med. geogr. trop (Amst.), 6, 193

McFarlane, A. L. and Branday, W. J. (1945). Brit. med. J., 1, 838.

Prabhu, M. B. (1940). Indian J. Pediat., 7, 121

Radhakrishna Rao, M. V. (1934). Indian'J. Pediat., 1, 166.

Radhakrishna Rao, M. V. (1935). Indian J. med. Res., 23, 69.

(1954). Malnutrition in African Mothers, Infants and Young Children. Report of 2nd Inter-African Conference on Nutrition, Gambia, 1952, pp. 101, 147, 358. London.

Ramachandra Rao, P. 1935). Cirrhosis of the Liver. Ph.D. Thesis. London. Cited by Brahmachari, U. and Brahmachari, P. (1938).

Rhodes, K. (1952). Brit. J. Nutr., 6, 198.

Rössle, R. (1930). In Handbuch der speziellen pathologischen. Anatomie und Histologie, ed. Henke, F. and Lubarsch, O., band 5 , teil 1, p. 449 . Berlin.

Selzer, G. and Parker, R. G. F. (1951). Amer. J. Path., 27, 885.

Sen, B. C. (1887). Indian med. Gaz., 22, 338.

Sherlock, S., Summerskill, W. H. J., White, L. P. and Phear, E. A. (1954). Lancet, 2, 453.

Srivastava, J. B. and Aikat, B. K. (1954). Trans. Sympos. on Liver Injury, Gwalior, Ind. Ass. Path., Bombay, p. 30. and in Indian J. med. Sci., 8, 446.

Stein, H. (1957). Brit. med. J., 1, 1946.

Stuart, K. L. and Bras, G. (1955). Brit. med. J., 2, 348.

- (1956). W. Indian med. J., 5, 33.

Suckling, P. V. and Campbell, J. A. H. (1957). J. trop. Pediat. 2, 173.

Walters, J. H. and Waterlow, J. C. (1954). Spec. Rep. Ser. med. Res. Coun. (Lond.), No. 285.

Waterlow, J. C. (1948). Ibid., No. 263.

Watson, C. J. and Hoffbauer, F. W. (1946). Ann. intern. Med., Wurm, H. (1939). Klin. Wschr., 18, 1527.

\section{Addendum}

A recent paper from South Africa has reported three typical cases of veno-occlusive disease in African children under the age of 18 months. All were verified at necropsy (Stein, 1957). 